\section{REVISTA CIENTÍFICA RURAL}

ISSN: $1413-8263 \quad 2525-6912$
Revista

Técnico-Científica

\title{
ENRAIZAMENTO IN VITRO DE CULTIVARES DE Gerbera hybrida (ASTERACEAE)
}

Tarcisio Rangel do Couto ${ }^{1,2}$, João Sebastião de Paula Araujo ${ }^{1,2}$, Leandro Miranda de Almeida ${ }^{1,3}$, João Paulo de Lima Aguilar ${ }^{1,4}$

${ }^{1}$ Universidade Federal Rural do Rio de Janeiro - UFRRJ, Instituto de Agronomia, Departamento de Fitotecnia, Seropédica, RJ; ${ }^{2}$ Doutor em Fitotecnia; ${ }^{3}$ Engenheiro Agrônomo; ${ }^{4}$ Mestre em Agricultura Orgânica.

RESUMO: A gérbera é considerada uma das flores de corte mais populares do mundo, devido a diversidade de cores e formas das flores. A propagação vegetativa in vitro é comumente usada nessa espécie para obtenção de mudas de forma mais rápida e em larga escala. Objetivou-se avaliar a influência de diferentes concentrações de auxina, sacarose e meio de cultura no enraizamento in vitro de cultivares de gérbera. Foram testadas três cultivares de gérbera ('Pacific', 'Igloo', 'Igor') em DIC fatorial 3x2x2, sendo três concentrações de ANA (0; 2,68 e 5,36 $\mu \mathrm{mol}$ $\left.\mathrm{L}^{-1}\right)$, duas concentrações de sais do meio MS (50\% e 100\%) e duas concentrações de sacarose (15 e $30 \mathrm{~g} \mathrm{~L}^{-1}$ ), com 10 repetições e a unidade experimental um frasco com $30 \mathrm{~mL}$ de meio e cinco plantas. Foi utilizado o meio $\mathrm{MS}$, contendo $7,5 \mathrm{~g} \mathrm{~L}^{-1} \mathrm{de}$ ágar e $\mathrm{pH}$ ajustado para 5,8. Após 30 dias foram contabilizados o número de folhas, número de raízes, massa fresca total e a porcentagem de sobrevivência das mudas após a aclimatização. Os tratamentos com adição de ANA resultaram em maior massa fresca, entretanto as mudas apresentaram-se com massas de calos na base, menor número de folhas, raízes mais espessas e em menor número. A sobrevivência das mudas foi alta após a aclimatização. Recomenda-se para enraizamento in vitro das gérberas estudadas, meio MS completo com $30 \mathrm{~g} \mathrm{~L}^{-1}$ de sacarose.

Palavras-chave: Micropropagação, meio de cultura, sacarose, ácido naftaleno acético.

\section{IN VITRO ROOTING OF Gerbera hybrida CULTIVARS (ASTERACEAE)}

ABSTRACT: The gerbera is considered one of the most popular cut flowers in the world, due to diversity of colors and shapes of the flowers. In vitro vegetative propagation is commonly used in this species to obtain seedlings more quickly on a large scale. The objective of this study was to evaluate the influence of different concentrations auxin, sucrose and culture medium in vitro rooting of gerbera cultivars. Three gerbera cultivars ('Pacific', 'Igloo', 'Igor') were tested in $3 \times 2 \times 2$ factorial DIC, with three ANA concentrations (0; 2.68 and $\left.5.36 \mu \mathrm{mol}^{-1}\right)$, two MS medium salts concentrations (50\% and 100\%) and two sucrose concentrations (15 
and $\left.30 \mathrm{~g} \mathrm{~L}^{-1}\right)$, with 10 repetitions and the experimental unit a $30 \mathrm{~mL}$ bottle of medium and five plants. MS medium containing 7,5 $\mathrm{g} \mathrm{L}^{-1}$ agar and $\mathrm{pH}$ adjusted to 5,8 was used. After 30 days were recorded the number of leaves, number of roots, fresh mass and survival after acclimatization were counted. The treatments with ANA addition resulted in a greater fresh mass, however seedlings presented with calluses masses at the base, less number leaves, thicker roots and lesser number. Seedling survival was high after acclimatization. Recommended for gerberas in vitro rooting complete MS medium with $30 \mathrm{~g} \mathrm{~L}^{-1}$ of sucrose.

Keywords: Micropropagation, culture medium, sucrose, naphthalene acetic acid.

\section{INTRODUÇÃO}

A gérbera é originária de Transvaal da África do Sul, também conhecida como margarida do Transvaal em alguns países. A planta é chamada de gérbera em homenagem a Traugott Gerber, um médico e naturalista alemão colecionador de plantas. Pertence à ordem Asterales, família Asteraceae (Compositae), tribo Mustisieae, subtribo Mustisiinae (MANNING et al., 2016). O gênero é composto por cerca de quarenta espécies, sendo a mais importante a Gerbera jamesonii Bolus Ex. Hook. Seu nome científico foi dado por um colecionador de plantas chamado Jameson, que descobriu a gérbera no Transvaal (DENG; BHATTARAI, 2018).

Atualmente a maioria das cultivares plantadas comercialmente são oriundas de hibridações entre Gerbera jamesonii x G. viridifolia, outra espécie sul africana. O híbrido resultante é conhecido como gérbera híbrida (Gerbera hybrida Hort). Tanto a Gerbera jamesonii quanto a Gerbera hybrida são diploides, possuem $2 n=2 x=50$ cromossomos e o capítulo composto por flores femininas e hermafroditas (CARDOSO et al., 2009).

Cerca de $80 \%$ do total de gérberas de corte e vaso comercializadas no país são originárias da região de Holambra (SP), e passam pelo Veiling-Leilão de Flores e Plantas Ornamentais. O mercado paulista absorve em torno de $65 \%$ de todo o volume produzido, portanto há um grande mercado potencial em outros estados para ser explorado (NEVES; PINTO, 2015). No Estado do Rio de Janeiro a produção de gérbera é feita comercialmente na região Serrana, com quase a totalidade dos 
produtores, nos municípios de Nova Friburgo, Bom Jardim, Petrópolis e Duas Barras.

Tratando-se do cultivo de flores de corte, a gérbera ganha em importância, por ser uma flor ideal para buquês, arranjos, enfeites e decorações, especialmente por sua variedade de cores e tamanhos. Também é necessário mencionar o crescimento e a importância da cultura de gérbera envasada. As gérberas são especialmente conhecidas por sua ampla gama de cores e formas, resultado de programas de melhoramento genético e técnica de micropropagação (DENG; BHATTARAI, 2018).

O método de propagação usual adotado para G. hybrida consiste no uso de estacas de rizoma, no entanto, a multiplicação de tecidos por este método é muito lenta para considerá-lo comercialmente viável. Logo, a propagação vegetativa in vitro ou micropropagação se apresenta como uma alternativa viável para obtenção de novas mudas de gérbera de forma mais rápida e em larga escala (PRASAD, 2014), pois esse procedimento compreende na totipotencialidade das células, resultando em mudas de alta qualidade genética e uniformes, além de constituir-se uma opção ao desenvolvimento de espécies que não podem ser propagadas por sementes ou macropropagação (AKTER et al. 2012).

Em sistema convencional de micropropagacão, as plantas cultivadas in vitro são condicionadas a ambiente fechado e asséptico, normalmente na presença de fitorreguladores e de açúcares como meio de cultura, a fim de fornecer carbono e energia (JUNGHANS; SOUZA, 2013). Desse modo, o meio de cultura precisa fornecer todas as substâncias essenciais para o crescimento dos tecidos, por isso, 0 mais adotado nesse procedimento é o MURASHIGE; SKOOG (1962) (MS), considerado um meio de cultura básico, composto de sais subdivididos em macronutrientes, micronutrientes, vitaminas e hexitol (mio-inositol) (JUNGHANS; SOUZA, 2013).

Ademais, é comum adicionar ao meio de cultura fitorreguladores como a auxina, pois algumas espécies enraízam com dificuldade ou não enraízam, e esses compostos desempenham um papel crucial na formação de raízes adventícias em 
plantas micropropagadas (MOHAMED; ÖZZAMBAK, 2014). Assim, verifica-se que na micropropagação, a adição de fitorreguladores ao meio de cultura é de extrema importância, pois diferentes combinações de concentrações destas substâncias propiciam um melhor crescimento das plantas produzidas, que são consideradas aptas quando apresentam número suficiente de raízes, para absorção de nutrientes e fornecer arquitetura necessária para o estabelecimento da planta após plantio em campo.

Neste contexto, o objetivo deste trabalho foi avaliar a influência de diferentes concentrações de auxina, sacarose e meio de cultura no enraizamento in vitro de cultivares de gérbera.

\section{MATERIAL E MÉTODOS}

O experimento foi realizado no Laboratório de Cultura de Tecidos Vegetais da Universidade Federal Rural do Rio de Janeiro (UFRRJ), localizada no município de Seropédica-RJ. As cultivares de gérbera utilizadas ('Pacific', 'Igor', 'Igloo') foram oriundas de floricultores da região Serrada do Estado do Rio de Janeiro, e as plantas matrizes foram cultivadas por três anos em casa de vegetação na UFRRJ antes do início da pesquisa de micropropagação. As brotações de gérbera foram oriundas da fase de multiplicação da micropropagação e estavam em quarto subcultivo.

Para cada cultivar de gérbera ('Pacific', 'Igloo' e 'Igor') foi instalado um experimento em delineamento inteiramente casualizado em fatorial $3 \times 2 \times 2$, sendo três concentrações de ANA (ácido 1-naftalenoacético) $\left(0,0 ; 2,68\right.$ e 5,37 $\mu \mathrm{mol} \mathrm{L} \mathrm{L}^{-1}$ ), duas concentrações de sais do meio MS (MURASHIGE; SKOOG, 1962) (50\% e $100 \%$ ) e duas concentrações de sacarose (Isofar $\left.{ }^{\circledR}\right)\left(15\right.$ e $30 \mathrm{~g} \mathrm{~L}^{-1}$ ). Cada tratamento continha dez repetições e a unidade experimental foi representada por um frasco de vidro $(120$ x $68 \mathrm{~mm})$ com $30 \mathrm{~mL}$ de meio de cultura e cinco brotações. O meio MS e as vitaminas de White (Phytotecnology Laboratories ${ }^{\circledR}$ ) utilizadas neste experimento, teve o seu pH ajustado para 5,8 antes da adição do ágar $\left(7,5 \mathrm{~g} \mathrm{~L}^{-1}\right.$ de ágar $\left.\operatorname{Vetec}^{\circledR}\right)$ e passou por autoclavagem num período de 15 minutos a 1,0 atm. e $121^{\circ} \mathrm{C}$.

Revista Científica Rural, Bagé-RS, volume 22, №1, ano 2020 
As brotações foram transferidas para os meios de cultivo propostos, e mantidas em sala de cultivo à temperatura de $26 \pm 2{ }^{\circ} \mathrm{C}$ e irradiância de $30 \mu \mathrm{mol} \mathrm{m} \mathrm{m}^{-2}$ $\mathrm{S}^{-1}$, provida por lâmpadas fluorescentes $\left(\mathrm{OSRAM}^{\circledR}\right.$, semelhante à luz do dia) e fotoperíodo de 16:8 horas (luz:escuro). Após 30 dias de enraizamento in vitro, realizou-se as seguintes avaliações: porcentagem de sobrevivência, matéria fresca total (MF) e o número de folhas (NF) e de raízes (NR).

Os dados obtidos foram testados quanto a normalidade e homogeneidade, pelos testes de Lilliefors e Shapiro-Wilk, respectivamente. Após esse procedimento, procedeu-se com a análise de variância e aplicação do teste de média de ScottKnott a $5 \%$ de probabilidade. Para as análises estatísticas, os dados foram processados pelo software Sisvar, e a elaboração dos gráficos pelo programa Excel 2013.

\section{RESULTADOS}

Para cada gérbera ('Pacific', 'Igloo' e 'Igor') foi feito uma ANOVA e observaram-se diferenças significativas (Tabela 1 e 2 ).

Tabela 1. Resumo da análise de variância para a número de folhas (NF), número de raízes (NR) e massa da matéria fresca (MF) de 'Pacific' após 30 dias de enraizamento in vitro.

Table 1. Analysis of variance summary for leaf number (NF), number of roots (NR) and fresh matter mass (MF) of

\begin{tabular}{ccccc}
\multicolumn{5}{c}{ 'Pacific' after 30 days in vitro rooting. } \\
\cline { 3 - 5 } Fontes de Variação & GL & NF & Quadrado Médio & NR \\
\hline ANA & 2 & $2,248613^{*}$ & $5,036396^{*}$ & $0,449811^{*}$ \\
Meio & 1 & $0,085556^{\text {ns }}$ & $1,632432^{\text {ns }}$ & $0,048910^{\text {ns }}$ \\
Sacarose (SAC) & 1 & $1,332870^{*}$ & $0,938315^{\text {ns }}$ & $0,130926^{*}$ \\
ANA x Meio & 2 & $0,522015^{\text {ns }}$ & $3,972478^{\text {ns }}$ & $0,076226^{\text {ns }}$ \\
ANA x SAC & 2 & $1,568193^{\text {ns }}$ & $0,940395^{\text {ns }}$ & $0,213892^{\text {ns }}$ \\
Meio x SAC & 1 & $0,669942^{\text {ns }}$ & $2,877547^{\text {ns }}$ & $0,000061^{\text {ns }}$ \\
ANA x Meio x SAC & 2 & $1,235526^{\text {ns }}$ & $1,317353^{\text {ns }}$ & $0,039859^{\text {ns }}$ \\
Erro & 25 & 0,264494 & 0,657881 & 0,1011 \\
\hline CV (\%) & \multicolumn{4}{c}{. }
\end{tabular}

*Significativo pelo teste $\mathrm{F}(\mathrm{P} \leq 0,05)$; ns - Não significativo pelo teste $\mathrm{F}(\mathrm{P} \leq 0,05)$.

Com relação a gérbera 'Pacific', observou-se significância somente nos fatores ANA e sacarose (Tabela 1). Para a variável NF, notou-se significância para 
os fatores ANA e sacarose. Para a variável NR, observou-se significância para o fator ANA e para a variável MF os fatores ANA e sacarose.

Para NF, observou-se que na ausência de auxina houve maior quantidade de folhas nas mudas de 'Pacific' (Figura 1A) e, que a concentração de $15 \mathrm{~g} \mathrm{~L}^{-1}$ de sacarose também proporcionou maior NF (Figura 1B).

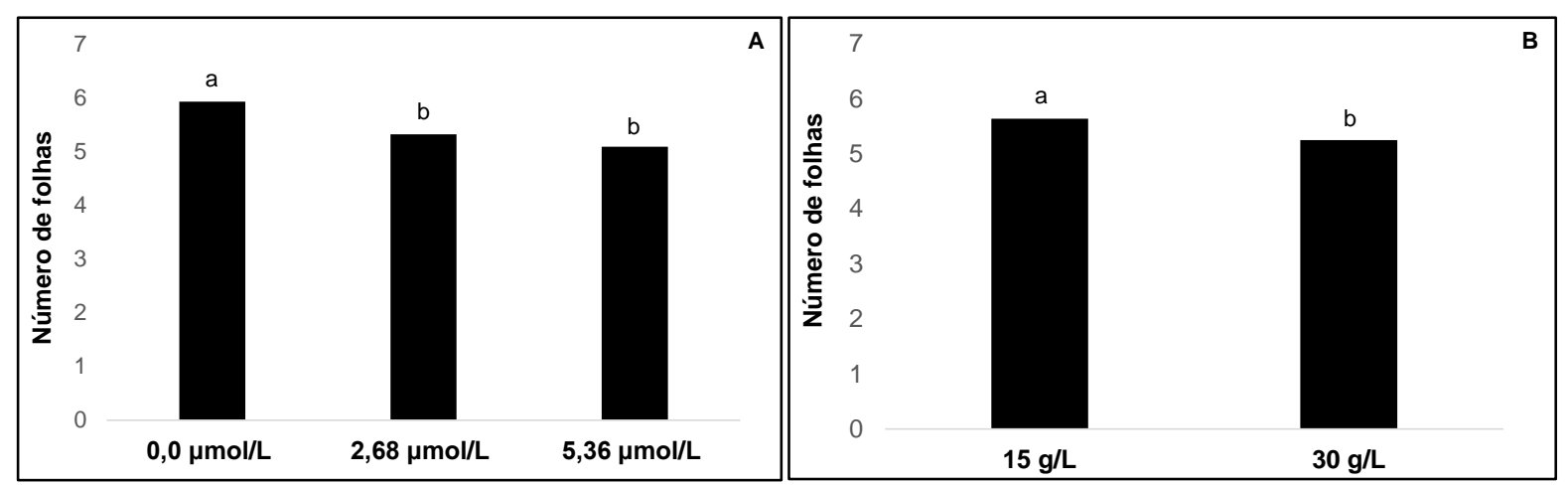

As letras diferem estatisticamente (Scott-Knott, $p>0,05)$.

Figura 1. Número de folhas de mudas da gérbera 'Pacific' após 30 dias de enraizamento in vitro em diferentes concentrações de ANA (A) e sacarose (B).

Figure 1. Number of seedling leaves 'Pacific' gerbera after 30 days in vitro rooting at different concentrations of ANA $(A)$ and sucrose (B).

Em relação à variável NR, observou-se que as mudas de 'Pacific' apresentaram maior quantidade de raízes em meio de cultura sem auxina ou com adição de adição de 2,68 $\mu \mathrm{mol} \mathrm{L}{ }^{-1}$ de ANA (Figura 2). 


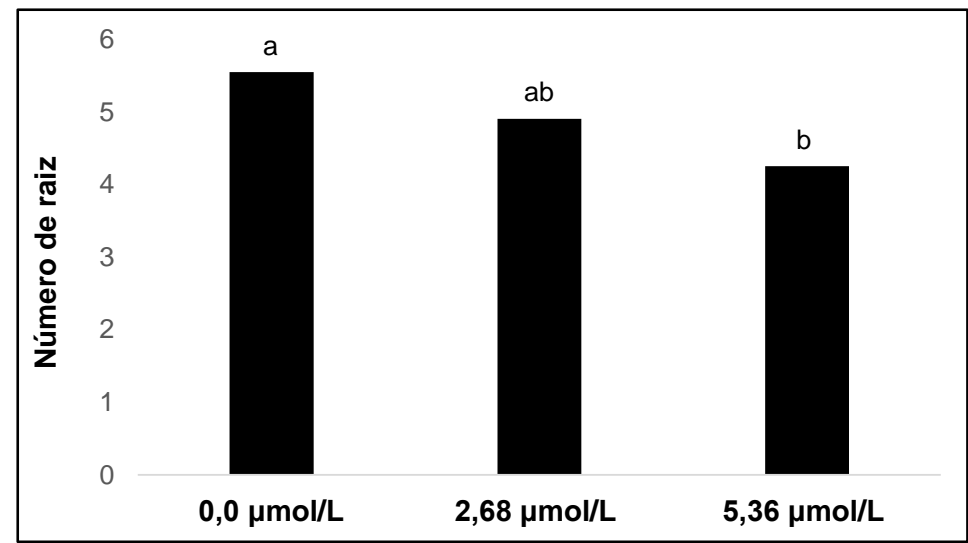

As letras diferem estatisticamente (Scott-Knott, $p>0,05)$.

Figura 2. Número de raízes de mudas da gérbera 'Pacific' após 30 dias de enraizamento in vitro em diferentes concentrações de ANA.

Figure 2. Number of roots of 'Pacific' gerbera after 30 days in vitro rooting at different concentrations of ANA.

Para MF, verificou-se que a adição de auxina proprocionou maior acúmulo de biomassa nas mudas de 'Pacific' (Figura 3A) e, que a concentração de $30 \mathrm{~g} \mathrm{~L}^{-1}$ de sacarose também proporcionou maior MF (Figura 3B).

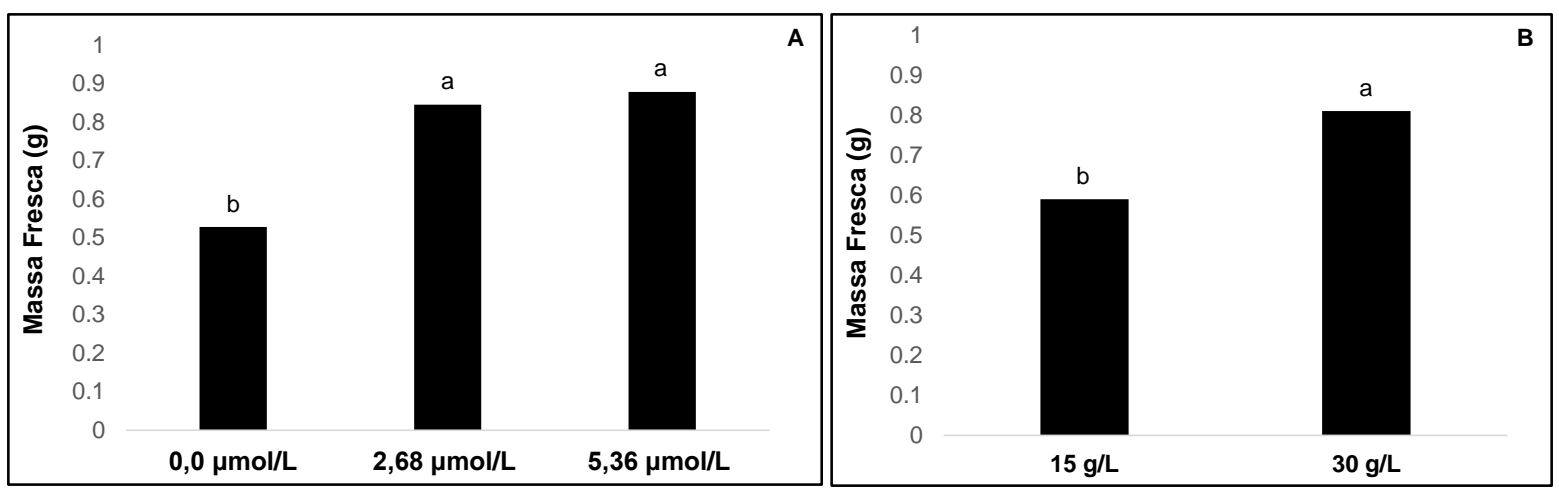

As letras diferem estatisticamente (Scott-Knott, $p>0,05)$.

Figura 3. Massa fresca de mudas da gérbera 'Pacific' após 30 dias de enraizamento in vitro em diferentes concentrações de ANA (A) e sacarose (B).

Figure 3. Fresh mass of 'Pacific' gerbera after 30 days in vitro rooting at different concentrations of $A N A(A)$ and sucrose $(B)$.

Com relação a gérbera 'Igloo', também foi observado significância somente nos fatores ANA e sacarose (Tabela 2). Para a variável NF, notou-se significância para os fatores ANA e sacarose. Para a variável NR não foi verificado diferença significância e para a variável MF o fator sacarose apresentou significância. 
Tabela 2. Resumo da análise de variância para a número de folhas (NF), número de raízes (NR) e massa da matéria fresca (MF) de 'Igloo' após 30 dias de enraizamento in vitro.

Table 2. Analysis of variance summary for leaf number (NF), number of roots (NR) and fresh matter mass (MF) of

\begin{tabular}{|c|c|c|c|c|}
\hline \multirow[t]{2}{*}{ Fontes de Variação } & \multirow[t]{2}{*}{$\mathrm{GL}$} & \multicolumn{3}{|c|}{ Quadrado Médio } \\
\hline & & NF & NR & MF \\
\hline ANA & 2 & $1,583333^{*}$ & $0,444444^{\text {ns }}$ & $0,000582^{\text {ns }}$ \\
\hline Meio & 1 & $0,027778^{\text {ns }}$ & $1,000000^{\text {ns }}$ & $0,040160^{\text {ns }}$ \\
\hline Sacarose (SAC) & 1 & $6,250000^{*}$ & $4,000000^{\text {ns }}$ & $0,551158^{*}$ \\
\hline ANA $x$ Meio & 2 & $0,361111^{\text {ns }}$ & $0,333333^{\text {ns }}$ & $0,014881^{\text {ns }}$ \\
\hline ANA $\times$ SAC & 2 & $3,250000^{\text {ns }}$ & $9,000000^{\text {ns }}$ & $0,007465^{\text {ns }}$ \\
\hline Meio $\times$ SAC & 2 & $4,694444^{\text {ns }}$ & $16,00000^{\text {ns }}$ & $0,013417^{\text {ns }}$ \\
\hline ANA $x$ Meio $\times$ SAC & 2 & $1,027778^{\text {ns }}$ & $2,775557^{\text {ns }}$ & $0,109579^{\text {ns }}$ \\
\hline Erro & 24 & 0,388889 & 0,416667 & 0,037799 \\
\hline CV (\%) & & 13,13 & 14,71 & 39,36 \\
\hline
\end{tabular}

*Significativo pelo teste $\mathrm{F}(\mathrm{P} \leq 0,05)$; ns - Não significativo pelo teste $\mathrm{F}(\mathrm{P} \leq 0,05)$.

Na variável NF foi verificado que nos tratamentos com ausência de auxina e adição de 2,68 $\mu \mathrm{mol} \mathrm{L} \mathrm{L}^{-1}$ de ANA, maior quantidade de folhas nas mudas de 'Igloo' (Figura 4A) e, que a concentração de $30 \mathrm{~g} \mathrm{~L}^{-1}$ de sacarose também proporcionou maior NF (Figura 4B).

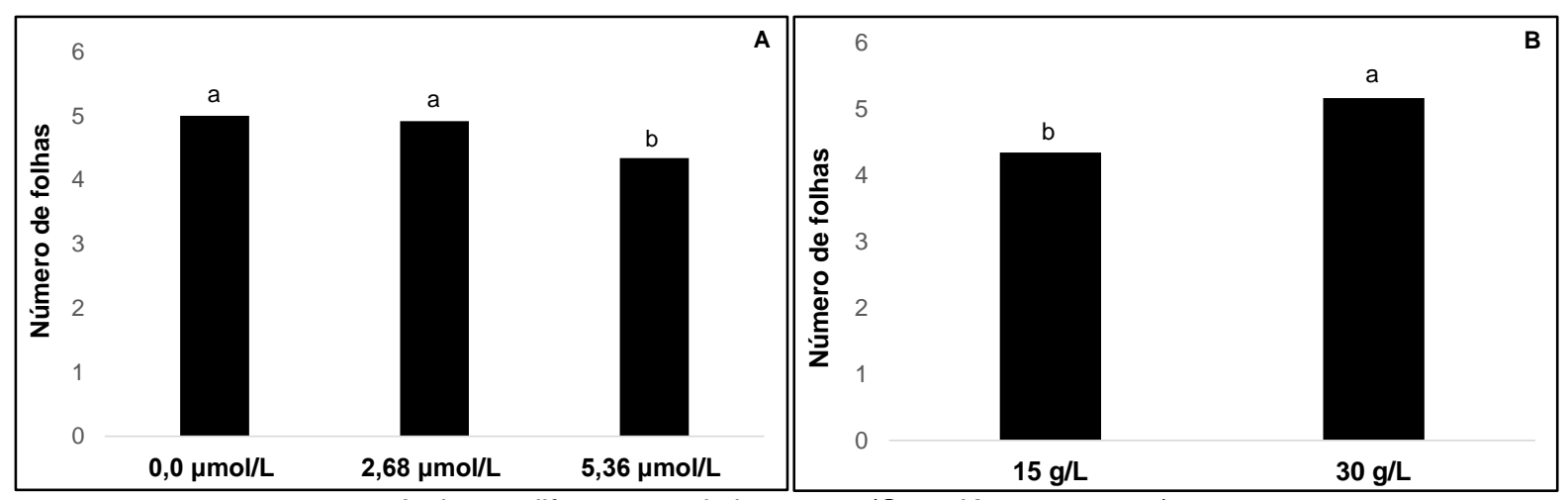

As letras diferem estatisticamente (Scott-Knott, $p>0,05)$.

Figura 4. Número de folhas de mudas da gérbera 'Igloo' após 30 dias de enraizamento in vitro em diferentes concentrações de ANA (A) e sacarose (B).

Figure 4. Number of seedling leaves "Igloo" gerbera after 30 days in vitro rooting at different concentrations of ANA $(A)$ and sucrose $(B)$.

Sobre a MF, verificou-se que as mudas de 'Igloo' apresentaram maior acúmulo de biomassa na concentração de $30 \mathrm{~g} \mathrm{~L}^{-1}$ de sacarose (Figura 5). 


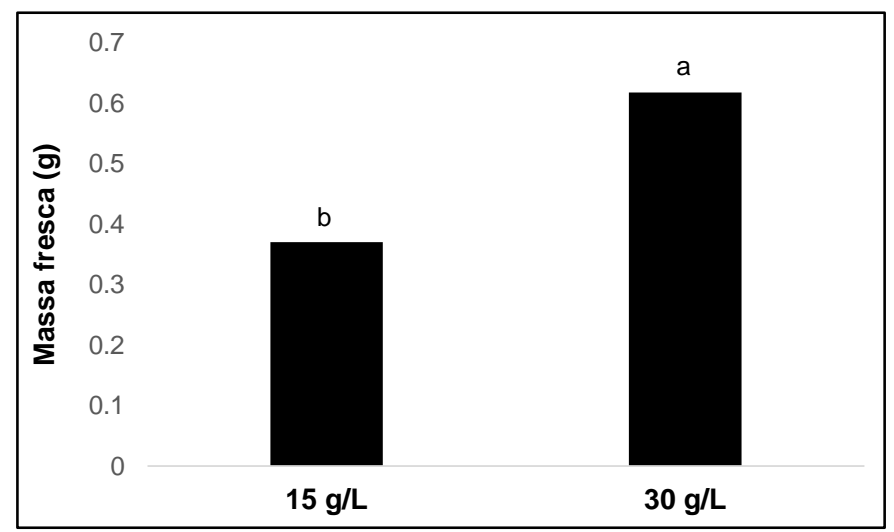

As letras diferem estatisticamente (Scott-Knott, $p>0,05)$.

Figura 5. Massa fresca de mudas da gérbera 'Igloo' após 30 dias de enraizamento in vitro em diferentes concentrações de sacarose.

Figure 5. Fresh mass of 'Igloo' gerbera after 30 days in vitro rooting at different concentrations of sucrose.

Quanto à gérbera 'Igor', não foi observado significância para os fatores ANA, meio de cultura e sacarose (Tabela 3 ).

Tabela 3. Resumo da análise de variância para a número de folhas (NF), número de raízes (NR) e massa fresca (MF) de 'Igor' após 30 dias de enraizamento in vitro.

Table 3. Analysis of variance summary for leaf number (NF), number of roots (NR) and fresh matter mass (MF) of 'Igor' after 30 days in vitro rooting.

\begin{tabular}{|c|c|c|c|c|}
\hline \multirow[t]{2}{*}{ Fontes de Variação } & \multirow[t]{2}{*}{$\mathrm{GL}$} & \multicolumn{3}{|c|}{ Quadrado Médio } \\
\hline & & NF & NR & MF \\
\hline ANA & 2 & $0,861111^{\mathrm{ns}}$ & $4,333333^{\text {ns }}$ & $0,020921^{\mathrm{ns}}$ \\
\hline Meio & 1 & $0,250000^{\text {ns }}$ & $1,777778^{\text {ns }}$ & $0,358881^{\mathrm{ns}}$ \\
\hline Sacarose (SAC) & 1 & $1,361111^{\mathrm{ns}}$ & $1,000000^{\text {ns }}$ & $1,286561^{\text {ns }}$ \\
\hline ANA $\times$ Meio & 2 & $0,583333^{\text {ns }}$ & $0,44444^{\text {ns }}$ & $0,055238^{\text {ns }}$ \\
\hline ANA $\times$ SAC & 2 & $0,861111^{\mathrm{ns}}$ & $3,00000^{\text {ns }}$ & $0,091207^{\mathrm{ns}}$ \\
\hline Meio x SAC & 1 & $0,027778^{\text {ns }}$ & $1,777778^{\text {ns }}$ & $0,992282^{\text {ns }}$ \\
\hline ANA*Meio*SAC & 2 & $1,694444^{\mathrm{ns}}$ & $1,444444^{\text {ns }}$ & $0,020783^{\text {ns }}$ \\
\hline Erro & 24 & 0,555556 & 0,416667 & 0,025931 \\
\hline CV (\%) & & 16,46 & 16,84 & 35,55 \\
\hline
\end{tabular}

A porcentagem de sobrevivência das mudas após 90 dias de aclimatização foi igual ou maior que $90 \%$, sem diferença significativa entre as cultivares. Observouse que a sobrevivência das mudas foi alta durante o período de aclimatização avaliado (outubro a dezembro). 


\section{DISCUSSÃO}

A maior MF foi obtida principalmente pela formação de calos na base da muda oriunda dos tratamentos com auxinas. Mas, essas mudas tiveram tamanho inferior àquelas do tratamento com ausência de auxina. Esse comportamento também foi observado por outros autores (RAHMAN et al., 2014; SHYLAJA et al., 2014), que recomendaram a ausência ou a adição em pequenas quantidades de auxinas na fase de enraizamento in vitro de gérbera, pois mudas maiores e mais desenvolvidas têm maior chance de sobrevivência durante a fase de aclimatização.

Rahman et al. (2014) testaram diferentes combinações das auxinas AIA, AIB e ANA no enraizamento in vitro de brotações de gérberas. Os autores notaram maior número médio de raízes por brotação quando foi utilizado $1,47 \mu \mathrm{mol} \mathrm{\textrm {L } ^ { - 1 }}$ de AIB. Shylaja et al. (2014) recomendaram a utilização de $0,54 \mu \mathrm{mol} \mathrm{L^{-1 }}$ de ANA para enraizamento in vitro de gérbera e também perceberam a formação de mudas menores e com calos em concentrações maiores de auxina.

Shabanpour et al. (2011) relataram que a melhor taxa de enraizamento das brotações de gérbera foi obtida quando utilizaram meio MS completo suplementado com $30 \mathrm{~g} \mathrm{~L}^{-1}$ de sacarose. Binh; Tai, (2018) verificaram maior NR e MF de mudas de orquídea (Paphiopedilum micranthum var. North Vietnam), quando cultivadas in vitro em meio MS (50\% força) e suplementado com $30 \mathrm{~g} \mathrm{~L}^{-1}$ de sacarose.

O número de folhas e a massa fresca das mudas foram afetados pela concentração de sacarose das cultivares Pacific e Igloo. Os dados obtidos são concordantes com as afirmações de vários autores que preconizam que a presença de carboidratos é essencial para o enraizamento in vitro de muitas espécies (KAVIANI et al., 2011; SHABANPOUR et al., 2011; SAETIEW; UMAMANIT, 2015); CHUNG et al., 2016). A formação in vitro de um sistema radicular funcional e bem desenvolvido é um dos pontos fundamentais para a sobrevivência das plantas na fase de aclimatização.

A sacarose atua como uma fonte de energia e fornece carbonos precursores para a biossíntese de componentes estruturais e funcionais, como carboidratos, aminoácidos e outras moléculas necessárias para o crescimento. O suprimento 
exógeno de açúcar pode ampliar as reservas de amido e sacarose nas plantas micropropagadas e favorecer a aclimatização, bem como acelerar as adaptações fisiológicas (BINH; TAI, 2018).

De modo geral, constatou-se repostas semelhantes entre as três cultivares analisadas nesta pesquisa, assim, as melhores respostas para as variáveis biométricas NF, NR e MF foram oriundas dos tratamentos que utilizaram meio de cultura MS (100\%), suplementado com sacarose $\left(30 \mathrm{~g} \mathrm{~L}^{-1}\right)$ e ausência de auxina. Embora em todos os tratamentos com adição de auxina tenham apresentado raiz nas três cultivares, a grande quantidade de calos fez com que as mudas tivessem tamanho reduzido (Figura 6).

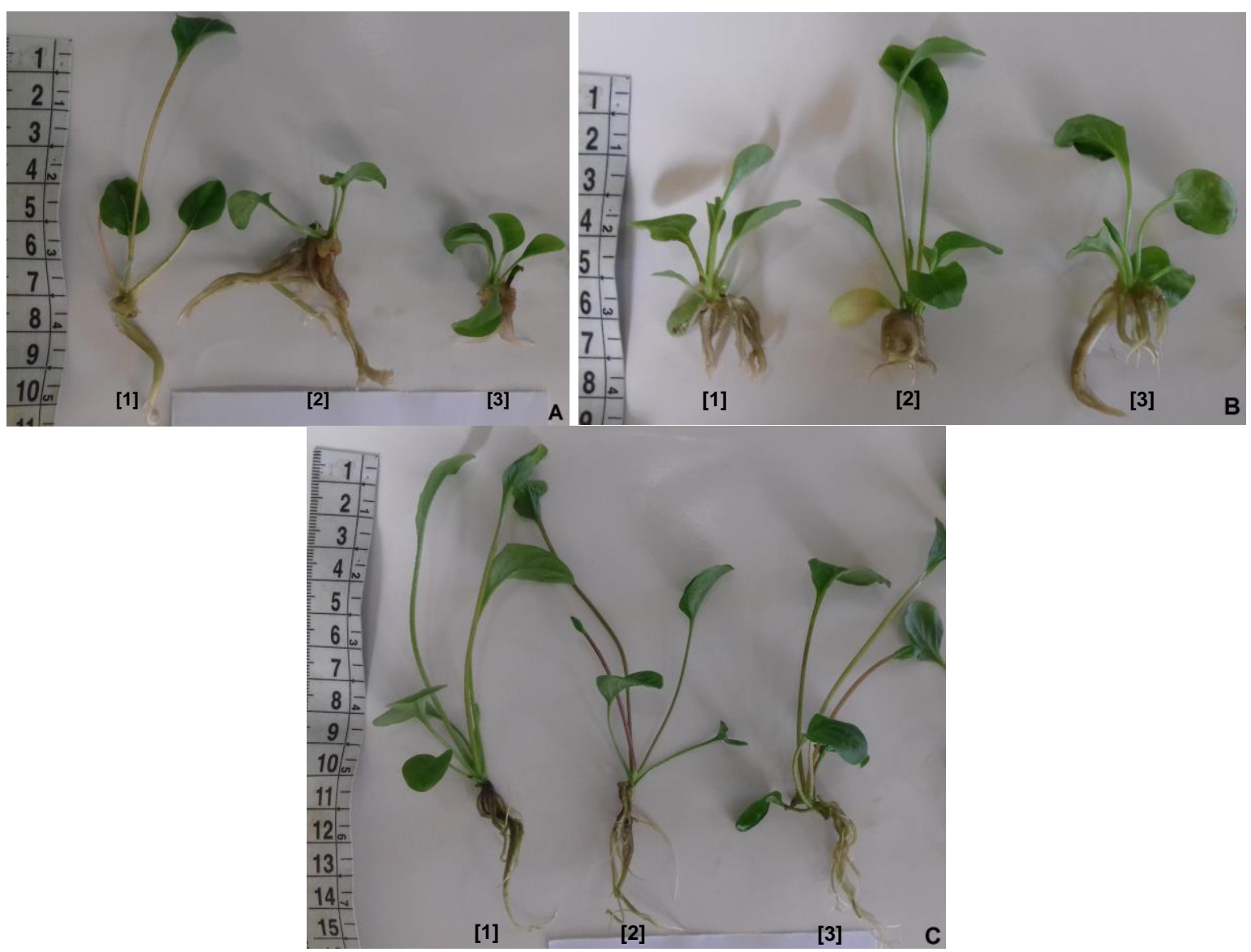

Figura 6. Mudas das cultivares de gérbera após 30 dias de enraizamento in vitro em meio MS (100\%) e $30 \mathrm{~g} \mathrm{~L}^{-1}$ de sacarose: (A) 2,68 $\mu \mathrm{mol} \mathrm{L}^{-1} \mathrm{ANA}$, (B) 5,36 $\mu \mathrm{mol} \mathrm{L}^{-1}$ ANA e (C) ausência de ANA.

Gérberas: [1] 'Pacific', [2] 'Igloo' e [3] 'Igor'.

Figure 6. Cultivars gerbera seedlings after 30 days in vitro rooting in MS medium (100\%) and $30 \mathrm{~g} \mathrm{~L}^{-1}$ sucrose: (A) $2.68 \mu \mathrm{mol} L^{-1} A N A$, (B) $5.36 \mu \mathrm{mol} L^{-1} A N A$ and (C) ANA absence. Gerberas: [1] 'Pacific', [2] 'Igloo' and [3] 'Igor'. 
A rizogênese é o resultado da interação de múltiplos fatores bioquímicos e ambientais, que desencadeiam processos morfogênicos dentro das plantas. Nem todas as plantas apresentam a capacidade de enraizar-se espontaneamente sob condições in vitro (CHUNG et al., 2016). Nesses caso, a incorporação de fitorreguladores no meio de cultura é necessário, para que, em conjunto com o níveis endógenos de hormônios, as concentrações sinérgicas favoráveis provoquem a iniciação o processo organogênico (MORA et al., 2015).

As auxinas são os fitorreguladores mais descrito em processos de indução de rizogênese de plantas in vitro, apresentando efeitos tanto ao nível radical como apical, onde o crescimento das plantas é induzida por mecanismos de alongamento celular, produto da capacidade de carga de nutrientes e metabolitos por estas moléculas (KUMAR et al., 2018).

Para o crescimento das raízes de plantas in vitro, geralmente baixa concentração ou ausência de auxina (dependendo da espécie e idade da planta) é necessário, porque as células dos meristemas radicais contêm um nível endógeno desse hormônio, a partir da parte aérea, suficiente para um alongamento normal. Porém, em outras espécies de plantas, para a formação de raízes adventícias, concentrações mais altas de auxinas são necessárias (FAN et al., 2017).

A esse respeito, com relação a variável número de raízes formadas nas três cultivares de gérbera, a diminuição da quantidade de raízes foi observada com o aumento da concentração de auxina. $O$ baixo número de raízes obtidas com o aumento da concentração de ANA, segundo Mora et al. (2015), indicam que existem efeitos inibitórios (formação de calos, engrossamento de raízes, estimulação de compostos fenólicos, entre outros) em concentrações relativamente mais altas desta auxina para as cultivares de gérbera estudadas.

Esizad et al. (2012) perceberam que a adição de ANA no enraizamento in vitro de brotações de fisianthus apresentou-se inibitório e que concentrações acima de 2,68 $\mu \mathrm{mol} \mathrm{L} \mathrm{L}^{-1}$ formaram mudas menores em relação ao tratamento com ausência. Entretanto, Souto et al. (2010) relataram que a adição de $2,68 \mu \mathrm{mol} \mathrm{L}^{-1}$ de ANA 
promoveu a neoformação e o crescimento longitudinal das raízes, e estimulou o desenvolvimento caulinar em plantas de Cattleya bicolor.

Chung et al. (2016) estudaram o enraizamento in vitro da gérbera 'Gold Eye' em meio MS (25\%, 50\%, $75 \%$ e $100 \%$ força), com diferentes concentrações de sacarose $\left(10,20,30\right.$ e $\left.40 \mathrm{~g} \mathrm{~L}^{-1}\right)$ e ANA $\left(0,0 ; 1,34 ; 2,68\right.$ e 5,36 $\left.\mu \mathrm{mol} \mathrm{L}^{-1}\right)$. Os autores observaram maior MF e NR quando foi utilizado meio MS (75\%) acrescido de $40 \mathrm{~g} \mathrm{~L}^{-}$ ${ }^{1}$ de sacarose e ausência de auxina.

Saetiew; Umamanit (2015) testaram diferentes concentrações do meio MS (0; 50; 75 e 100\%) e sacarose $\left(0 ; 5 ; 15\right.$ e $\left.30 \mathrm{~g} \mathrm{~L}^{-1}\right)$ durante o enraizamento in vitro da planta ornamental lilium (Lilium formolongo) e relataram maior NF e MF nos tratamentos com meio MS (100\%) suplementado com $30 \mathrm{~g} \mathrm{~L}^{-1}$ de sacarose.

Kaviani et al. (2011) testaram diferentes combinações de meio e sacarose no enraizamento in vitro de brotações de goivo (Matthiola incana), e confirmaram que o meio MS completo $+30 \mathrm{~g} \mathrm{~L}^{-1}$ de sacarose e ausência de auxina, apresentou maior NF, NR e MF para esta planta ornamental.

Diniz et al. (2014), avaliaram diferentes concentrações da formulação dos sais macronutrientes do meio MS (25; 50; 75 e 100\%) combinado com diferentes concentrações de $\operatorname{AIB}\left(0,0 ; 0,50\right.$ e $\left.4,92 \mu \mathrm{mol} \mathrm{L}^{-1}\right)$ no enraizamento in vitro de minirosa. Os autores recomendaram o MS completo (100\%) e ausência de auxina nessa fase da micropropagação, pois observaram, mesmo em pequenas concentrações, que o AIB induziu a formação de raízes curtas, grossas e de má qualidade.

\section{CONCLUSÕES}

Para o enraizamento in vitro das cultivares de gérbera 'Pacific', 'Igloo' e 'Igor' recomenda-se a utilização de meio MS completo, suplementado com $30 \mathrm{~g} \mathrm{~L}^{-1}$ de sacarose e ausência de ANA. As condições da casa de vegetação proporcionaram alta porcentagem de sobrevivência das mudas das cultivares de gérbera no período avaliado. 


\section{AGRADECIMENTOS}

À UFRRJ, e ao Curso de Pós-Graduação em Fitotecnia-UFRRJ. À Universidade Federal Fluminense (UFF) e aos floricultores que doaram as cultivares de gérberas para a realização da pesquisa de doutorado do primeiro autor.

\section{REFERÊNCIAS}

AKTER, N.; HOQUE, M. I.; SARKER, R. H. In vitro propagation in three varieties of gerbera (Gerbera jamesonii Bolus.) from flower bud and flower stalk explants. Plant Tissue Culture \& Biotechnology, v. 22, n. 2, p. 143-152, 2012.

$\mathrm{BINH}$, V. T.; TAl, S. S. K. Effects of plant growth regulators and sucrose on the regeneration of Paphiopedilum micranthum var. North Vietnam. Vietnam Journal of Agricultural Sciences, v. 1, n.1, p.11-20, 2018.

CARDOSO, R. D. L.; GRANDO, M. F.; BASSO, S. M. S.; SEGEREN, M. I.; AUGUSTIN, L., SUZIN, M. Chromosome number, pollen viability and gerbera hybridization. Horticultura Brasileira, v. 27, p. 40-44, 2009.

CHUNG, M. Y.; KIM, M. B.; CHUNG, Y. M.; NOU, I. S.; KIM, C. K. In vitro shoot regeneration and genetic transformation of the gerbera (Gerbera hybrida Hort.) cultivar 'Gold Eye'. Journal of Plant Biotechnology, v. 43, p. 255-260, 2016.

DENG, Z.; BHATTARAI, K. Gerbera. In: VAN HUYLENBROECK, J. (Ed.) Ornamental Crops, Handbook of Plant Breeding 11. Dordrecht, The Netherlands: Springer, 2018. p.407-438.

DINIZ, J. D. N.; ALMEIDA, J. L.; OLIVEIRA, A. B.; VIDAL, F. R. Multiplicação e enraizamento in vitro de Minirosa. Revista Ciência Agronômica, v. 45, n.1, p. 68-73, 2014.

ESIZAD, S. G.; KAVIANI, B.; TARANG, A.; ZANJANI, S. B. Micropropagation of lisianthus (Eustoma grandiflorum) an ornamental plant. Plant Omics Journal, v. 5, n. 3, p. 314-319, 2012.

FAN, S.; JIANB, D.; WEI, X.; CHEN, J.; BEESON, R. C.; ZHOU, Z.; WANGA, X. Micropropagation of blueberry 'Bluejay' and 'Pink Lemonade' through in vitro shoot culture. Scientia Horticulturae, v. 226, p. 277-284, 2017.

JUNGHANS, T. G.; SOUZA, A. S. Aspectos práticos da micropropagação de plantas. 2 ed. Brasília, DF : Embrapa, 2013. 407 p. 
KAVIANI, B.; HESAR, A. A.; KHARABIAN-MASOULEH, A. In vitro propagation of Matthiola incana (Brassicaceae) - an ornamental plant. Plant Omics Journal, v. 4, n. 7, p. 435-440, 2011.

KUMAR, A.; KUMAR, A.; SHARMA, V.; MISHRA, A.; SINGH, S.; KUMAR, P. In vitro regeneration of gladiolus (Gladiolus hybrida L.): optimization of growth media and assessment of genetic fidelity. International Journal of Current Microbiology and Applied Sciences, v. 7, n. 10, p. 2900-2909, 2018.

MANNING, J. C.; SIMKA, B.; BOATWRIGHT, J. S.; MAGEE, A. R. A revised taxonomy of Gerbera sect. Gerbera (Asteraceae: Mutisieae). South African Journal of Botany, v. 104, p. 142-157, 2016.

MOHAMED, S. A.; ÖZZAMBAKB, M. E. Shoot regeneration capacity of in vitro cultures of some gerbera (Gerbera jamesonii Bolus) explants. Sudanese Journal of Agricultural Sciences, v. 1, p. 24-29, 2014.

MORA, D. F.; CERDAS, R. C.; MARCHENA, L. A.; DURÁN, A. S.; ULLOA, C. A. Enraizamiento de vitroplantas de membrillo (cydonia oblonga) por medio de inmersión temporal automatizada y su aclimatación. Revista Brasileira de Fruticultura, v. 37, n. 3, p. 739-747, 2015.

MURASHIGE, T.; SKOOG, F. A revised medium for rapid growth and bioassay with tobacco tissue cultures. Physiologia Plantarum, v. 15, n. 1, p. 473-497, 1962.

NEVES, M. F.; PINTO, M. J. A. Mapeamento e quantificação da cadeia de flores e plantas ornamentais do Brasil. São Paulo: OCESP, 2015. Câmara Setorial Federal de Flores e Plantas Ornamentais, Instituto Brasileiro de Floricultura (IBRAFLOR). $132 \mathrm{p}$.

PRASAD, M. P. In vitro optimization of growth hormones in the micropropagation of Gerbera species. International Journal of Current Biotechnology, v. 2, n. 2, p. 1-5, 2014.

RAHMAN, M.; AHMED, B.; ISLAM, R.; MANDAL, A.; HOSSAIN, M. A Biotechnological approach for the production of red gerbera (Gerbera Jamesonii Bolus). Nova Journal of Medical and Biological Sciences, v. 2 n. 1, p. 1-6, 2014.

SAETIEW, K.; UMAMANIT, T. Micropropagation of Lilium formolongo via leaf explants. International Journal of Agricultural Technology, v. 11, n.5, p. 1255-1262, 2015.

SHABANPOUR, K.; SHARIFI, A.; BAGHERI, A.; MOSHTAGHI, N. Effect of genotypes and culture medium on shoot regeneration and proliferation of Gerbera jamesonii. African Journal of Biotechnology, v. 10, n. 57, p. 12211-12217, 2011.

SHYLAJA, M. R.; SASHNA, P.; CHINJUSHA, V.; NAZEEM, P. A. An efficient micropropagation protocol for Gerbera jamesonii bolus from flower buds. International Journal of Plant, Animal and Environmental Sciences, v. 4, n. 1, p. 641643, 2014. 
SOUTO, J. S.; MORIMOTO, J. M.; FERREIRA, W. M.; NAKABASHI, M.; SUZUKI, R. $M$. Efeitos do ácido naftalenoacético no desenvolvimento in vitro de Cattleya bicolor Lindl. (Orchidaceae). Revista Brasileira de Biociências, v. 8, n. 2, p. 179-185, 2010. 